\title{
ESTADO, COMUNIDAD Y MERCADO EN LOS MONTES MUNICIPALES EXTREMEÑOS (1855-1924) *
}

ANTONIO MIGUEL LINARES LUJÁN

Universidad de Extremadura

\section{RESUMEN}

Este trabajo pretende evaluar el alcance de la intervención estatal en el proceso de redefinición de los derechos de propiedad. El objetivo fundamental es analizar, a través del estudio de los montes municipales extremeños, el grado de aplicación de los dos mecanismos de actuación previstos por la legislación liberal en el ámbito de los patrimonios de titularidad pública: la enajenación definitiva de la propiedad y la inspección técnica de la producción. Aun matizando el protagonismo de la ley, la investigación confirma plenamente el éxito de la fórmula privatizadora en el suroeste peninsular. Menos evidente resulta, sin embargo, el triunfo de la vía interventora. Es aquí, precisamente, donde quedan reflejadas las dificultades del Estado para lograr una aplicación homogénea de la norma en todo el territorio nacional.

N. de E.: Fecha de recepción del artículo: junio 1999.

Fecha de la versión definitiva: diciembre 2000.

* Una primera versión en inglés de este trabajo fue presentada, en octubre de 1998, al seminario «Social and economic change in rural societies», celebrado en la Universitat Autònoma de Barcelona y organizado por la European Graduate School for Training in Economic and Social Historical Research (ESTER). Para la realización de dicha versión, el autor contó con una de las ayudas económicas que concede anualmente el Banco de España. Además de las inestimables sugerencias vertidas por los evaluadores anónimos, el texto definitivo ha tenido en cuenta las sensatas apreciaciones de Ramón Garrabou, Santiago Zapata Blanco, Ignacio Jiménez Blanco, Enrique Llopis Agelán y Miguel Vermehren de Resseguier. De las lagunas resultantes, el autor es el único responsable. 


\section{ABSTRACT}

This work aims to evaluate the extent of State intervention in the process of the redefinition of property rights. By studying the evolution of municipal woodlands in Extremadura, my main objective is to analyse the two mechanisms of intervention in the area of publicly held property: the definitive privatisation of property and the technical inspection of production. Even if we play down the effect of legislation, the present investigation confirms the full success of the privatisation formula employed in the Sapnish Southwest. State control over production, however, was far less efficient. Precisely in this area we can see how difficult it is for the State to enforce a comprehensively policy throghout its territory.

\section{INTRODUCCIÓN}

Siguiendo las categorías básicas del pensamiento económico liberal, la historiografía contemporánea ha interpretado la desaparición de los bienes comunales como algo históricamente inevitable. No obstante, a la luz de los trabajos realizados durante los últimos años, la realidad del proceso descomunalizador en el mundo occidental parece haber sido bastante menos uniforme de lo que tradicionalmente se ha supuesto. Sin restar importancia al avance del individualismo agrario y a la consiguiente disminución de los espacios de titularidad colectiva desde mediados del Setecientos, hoy en día resulta evidente que las formas que adquirió el fenómeno en el continente europeo, lejos de ser unívocas, quedaron marcadas por la heterogeneidad. Así, por ejemplo, los cerramientos británicos presentaron características muy distintas a las particiones de comunales efectuadas en Austria y Prusia o a las privatizaciones llevadas a cabo en Francia. Igualmente, los repartos de baldíos realizados en España y Portugal durante la segunda mitad del siglo xvil no actuaron sobre los bienes comunales de la misma manera que lo hicieron las desamortizaciones del Ochocientos ${ }^{1}$.

Tampoco el debate teórico estuvo caracterizado por la uniformidad de criterios. Frente a los ideólogos más ortodoxos, algunos sectores comprometidos con la causa liberal trataron de poner coto a la expansión del individualismo, reconociendo los efectos desestabilizadores de la privatización sobre las formas tradicionales de organización agraria ${ }^{2}$. Asimismo,

${ }^{1}$ Véanse, entre otros, Rodrigues (1987), Thompson (1991), Corona (1996), Mayaud (1996), Neeson (1996) e Iriarte (1996b).

${ }^{2}$ En este sentido resultan fundamentales los trabajos de Grossi (1986) y Giménez (1990). 
a lo largo de la segunda mitad del siglo xxx arraigó en Europa Occidental la tesis difundida por los técnicos forestales alemanes acerca de la necesidad de mantener algunas superficies de titularidad colectiva bajo control estatal. Para los padres de la dasonomía, la lógica de la maximización del beneficio invitaba a los particulares a sobreexplotar los espacios arbolados sin tener en cuenta las funciones protectoras que el mercado no podía remunerar. Comprobada la benéfica influencia que los bosques ejercían sobre el clima o sobre el régimen hídrico, resultaba preciso asegurar la conservación del monte alto a través de instituciones que garantizaran la generación de externalidades positivas. Desde este punto de vista, el sector público aparecía como la única entidad capaz de combinar el interés por el beneficio económico con la preocupación por el sostenimiento ecológico. El Estado debía, por tanto, asumir la propiedad de los montes de utilidad pública y, al mismo tiempo, ejercer un control exhaustivo sobre aquellos otros que continuaran perteneciendo a las comunidades rurales ${ }^{3}$. Quedaba así delimitada la tesis del forestalismo público europeo y, con ella, la idea de la incompatibilidad entre propiedad colectiva y conservación de la naturaleza ${ }^{4}$.

En España, el discurso intelectual sobre el futuro de los bienes comunales no fue ajeno a la diversidad de criterios manifestada en otras zonas del continente. Dentro del propio credo liberal, algunos autores calificaron negativamente los efectos provocados por el avance del individualismo competitivo en el mundo rural y propusieron la moderación de los programas maximizadores del liberalismo económico. De la misma manera, la literatura forestal decimonónica desarrolló una insistente campaña de estatalización de los montes públicos españoles claramente influida por los principios de la dasonomía germánica. Por el contrario, el sector más crítico con el afianzamiento del pensamiento liberal, no sólo rechazó la supuesta incompatibilidad entre titularidad colectiva y crecimiento agrario, sino que llegó a defender la extensión de la propiedad comunal en detrimento de la propiedad individual ${ }^{5}$.

${ }^{3}$ Véase Kalaora y Savoye (1986) y James (1990).

4 El debate en torno a este último punto ha perdurado hasta la actualidad a través de la polémica suscitada por el artículo de Hardin (1968) sobre la llamada «tragedia de los comunales». Pueden verse, al respecto, los trabajos de Thompson (1975), McCay y Acherson (1987), Berkes (1989), Aguilera (1991), Cobo, Cruz y González de Molina (1992) y Sala (1995).

5 Véanse, por ejemplo, los trabajos de Nieto (1964), Gómez Mendoza (1992) y Casals (1988). 
La pluralidad que presentó el debate teórico quedó igualmente reflejada en la evolución de la actividad legislativa. De hecho, pese a los fuertes impulsos que recibió el proceso desamortizador por parte de los gobiernos liberales, algunos gabinetes utilizaron los resortes de la ley para intentar garantizar la participación de los sectores más desfavorecidos de la sociedad en la redefinición de los derechos de propiedad. Las diferencias en los objetivos generaron también diferencias en los mecanismos arbitrados para proceder a la privatización. Así, junto a la nacionalización y venta por parte del Estado, la apropiación individual de los antiguos bienes comunales fue legalizada en ciertos momentos a través de otras fórmulas menos conocidas como las redenciones de censos, los repartos gratuitos, las cesiones enfitéuticas o las legitimaciones de roturaciones arbitrarias. Por otro lado, la legislación española tampoco pudo quedar al margen del forestalismo público europeo y tuvo que centralizar la gestión de buena parte de los montes de titularidad pública. Además, no siempre los gobiernos apostaron por la privatización o por la estatalización de los espacios tradicionalmente destinados al aprovechamiento colectivo. $\mathrm{Si}$, en algunas ocasiones, el proceso legal de redefinición de los derechos de propiedad quedó paralizado, en otras, fue justamente el rescate de los antiguos bienes comunales el objetivo fundamental del legislador.

A los vaivenes de la reglamentación estatal, no todas las regiones ni todas las comarcas españolas respondieron de la misma manera ${ }^{6}$. En algunos lugares, los proyectos del liberalismo fueron fuertemente contestados por las comunidades locales y tuvieron que ser abandonados o acomodados a las condiciones de partida. Cuando la privatización contó con el apoyo de la sociedad rural, el modelo de crecimiento agrario adoptado, no sólo dependió de las características físicas de cada territorio, sino también de las fórmulas empleadas para proceder a la adjudicación de los espacios colectivos. A veces, la restricción de los usos comunales como consecuencia de la intervención estatal desencadenó fenómenos de deforestación en los que intervino activamente la propia comunidad campesina. Otras veces, la reforma agraria liberal no necesitó imponer sus principios en un mundo rural caracterizado por la gestión colectiva de los recursos naturales. Es más, el mejor conocimiento del proceso privatizador decimonónico ha revelado, no sólo que en múltiples ocasiones el individualismo competitivo precedió a la ley, sino que, incluso, a pesar de ella, los pueblos gozaron

6 Cabe citar, entre otros muchos, los trabajos de Díez Espinosa (1986), Araque (1990), Montiel (1990), Balboa (1990), Artiaga (1991), López Estudillo (1992), Lana (1992), Manuel (1994), Moreno (1996), Iriarte (1996b), Jiménez Blanco (1996), Sabio (1997) y Sala (1997). 
de la suficiente capacidad de maniobra como para interpretar en beneficio propio las directrices emanadas de la autoridad central.

Hasta hace muy poco tiempo, sin embargo, la historiografía española ha identificado sin demasiadas reservas la penetración del mercado en el mundo rural con el surgimiento del liberalismo. La correlación entre ambos acontecimientos ha llegado a ser tan popular que incluso, para los más críticos, el proceso de privatización de los patrimonios de titularidad pública ha dejado de tener entidad propia para convertirse en una mera variable dependiente del proceso de consolidación de la reforma agraria liberal. De este modo, el Estado decimonónico ha pasado a ser considerado en la historia económica española como un ente autónomo capaz de imponer por decreto las relaciones capitalistas de producción. Pocos han reconocido la indiscutible responsabilidad de la sociedad en la cambiante orientación de la política estatal o la capacidad de adaptación de la actividad económica tradicional a la mercantilización de los procesos productivos. De ahí, las contradicciones en las que a veces ha incurrido la literatura española a la hora de interpretar el desigual avance de las tendencias individualizadoras en el mundo rural o la heterogénea evolución de las formas de resistencia frente a la descomunalización de los espacios colectivos.

En las páginas que siguen no pretendo resolver todas las dudas que suscita el estudio del proceso privatizador. Sólo intento matizarlas a través del análisis de una realidad espacial muy concreta (Extremadura) y de un marco temporal muy delimitado (1855-1924). La importancia que adquiere en tierras extremeñas el patrimonio forestal de los pueblos a mediados del siglo XIX justifica sobradamente la elección de esta parte del país para testar las distintas interpretaciones que concurren en el debate. Por su parte, la acotación cronológica del período responde al momento en el que la presencia del Estado, dentro del largo y azaroso proceso de privatización, parece más clara desde el punto de vista legislativo: la Ley General de Desamortización de 1 de mayo de 1855 ratifica la apropiación individual de los terrenos concejiles y el Estatuto Municipal de 8 de marzo de 1924 sanciona la paralización definitiva de las transferencias. Entre una y otra fecha, la venta en pública subasta de la propiedad y la intervención técnica de la producción alcanzan un protagonismo en los montes municipales extremeños tan sólo comparable al que adquieren paralelamente los movimientos de protesta contra la injerencia estatal. 


\section{EL PATRIMONIO FORESTAL DE LOS MUNICIPIOS EXTREMEÑOS A MEDIADOS DEL SIGLO XIX}

La imperfección de las fuentes existentes impide conocer con exactitud la superficie forestal ocupada por el patrimonio municipal extremeño a mediados del siglo XIx. No obstante, el seguimiento exhaustivo de los inventarios elaborados por las autoridades locales entre 1845 y 1855 permite obtener una imagen bastante elocuente de la importancia tradicionalmente atribuida por la literatura regional a la riqueza rústica de los pueblos (Cuadro 1). Considerando tan sólo los terrenos de carácter forestal, los recuentos $e$ interrogatorios de los años cuarenta y cincuenta arrojan una cifra superior al millón de hectáreas, repartidas entre 1.923 fincas. En términos relativos, la superficie ocupada por los montes de los pueblos (propios, arbitrios y comunes) representa a mediados del siglo XIX más de la cuarta parte de la extensión geográfica total y más de la tercera parte de la superficie productiva de la región.

Por lo que respecta a la especie arbórea dominante, la disgregación de las cifras obtenidas a partir de los inventarios locales permite constatar la importancia relativa del monte mediterráneo. La encina y el alcornoque

\section{CUADRO 1}

Superficie Forestal de los Patrimonios Municipales Extremeños en 1855

\begin{tabular}{|c|c|c|c|c|c|c|}
\hline \multirow{2}{*}{$\begin{array}{c}\text { Especie } \\
\text { Dominante }\end{array}$} & \multicolumn{2}{|c|}{ Badajoz } & \multicolumn{2}{|c|}{ Cáceres } & \multicolumn{2}{|c|}{ Extremadura } \\
\hline & Hectáreas & Porcentaje & Hectáreas & Porcentaje & Hectáreas & Porcentaje \\
\hline Encina ............................. & 338.238 & 67,2 & 411.822 & 59,6 & 750.060 & 62,8 \\
\hline Alcornoque................ & 3.005 & 0,6 & 21.666 & 3,1 & 24.671 & 2,1 \\
\hline Roble ........................... & 37.701 & 7,5 & 129.542 & 18,8 & 167.243 & 14,0 \\
\hline Pino .............................. & 392 & 0,1 & 7.932 & 1,1 & 8.324 & 0,7 \\
\hline Otros........................... & 498 & 0,1 & 1.981 & 0,3 & 2.479 & 0,2 \\
\hline Matorral .................... & 35.811 & 7,1 & 87.866 & 12,7 & 123.677 & 10,4 \\
\hline Raso........................... & 64.831 & 12,9 & 27.236 & 4,0 & 92.067 & 7,6 \\
\hline Desconocido ........... & 23.195 & 4,5 & 2.622 & 0,4 & 25.817 & 2,2 \\
\hline Total ........................ & 503.671 & 100,0 & 690.667 & 100,0 & 1.194 .338 & 100,0 \\
\hline
\end{tabular}

Fuente: Propios, Arbitrios y Comunes (1835-1855), Relación (1846), Interrogatorio (1851), Inventario (1855), Dirección General de Agricultura (1859, 1864 y 1901), Dirección General de Propiedades (1897) y Planes de Aprovechamientos (1873-1925: Estados de 1925). 
en monte alto y la jara, el tomillo, el brezo, la retama, y el lentisco en monte bajo representan casi el 75 por 100 de la superficie ocupada por el patrimonio forestal de los municipios extremeños. Se trata de especies perfectamente adaptadas a la aridez e irregularidad del clima mediterráneo y a la pobreza de los suelos pardos meridionales, circunstancias ambas que explican la generalizada presencia de tales variedades en Extremadura. El roble, en cambio, pese a la significativa participación que adquiere en el total regional, tan sólo aparece documentado en la zona norte y nordeste de la provincia de Cáceres y en la zona sur y nordeste de la provincia de Badajoz, coincidiendo con las tierras más húmedas y montañosas de la región. Parecida distribución geográfica presentan las formaciones de pino, castaño, aliso, fresno, álamo y chopo, aunque ninguna de ellas supera el 1 por 100 de la superficie total contabilizada. Mayores proporciones alcanzan los montes en los que la vegetación arbórea y arbustiva ha sido prácticamente eliminada en favor del aprovechamiento agropecuario extensivo (monte raso). Este tipo de terrenos, caracterizado por la presencia de gramíneas, leguminosas y algunas quercíneas, aparece repartido por toda la geografía regional, pero adquiere especial relevancia en las comarcas donde la llanura y la penillanura dominan el paisaje.

La importancia que reviste la superficie forestal desarbolada y la frecuencia con la que las autoridades locales emplean los términos «poco poblado» o «muy poco poblado» para referirse a los montes de los pueblos son pruebas evidentes de la intervención humana en el bosque autóctono del suroeste peninsular. Es más, todo parece indicar que, a mediados del siglo $\mathrm{XX}$, los patrimonios forestales administrados por los municipios extremeños están constituidos en un alto porcentaje por terrenos medianamente adehesados. Este detalle resulta fundamental para comprender las especiales circunstancias en las que se desenvuelve el proceso de privatización de los montes concejiles y comunales en Extremadura.

La dehesa extremeña es una explotación agro-silvo-pastoril en la que la gestión productiva de la labor y del arbolado está condicionada por la actividad pecuaria. Es, ante todo, una singular adaptación del hombre a las condiciones naturales adversas: suelos pobres, temperaturas elevadas y precipitaciones escasas. La intervención humana consiste en ganar superficie de pasto o, eventualmente, de cultivo a la tierra poblada de exuberante vegetación (monte pardo). Mediante rozas periódicas en monte bajo y talas controladas en monte alto, el bosque impenetrable de quercíneas adquiere con el tiempo un uso polivalente y alternativo: el suelo y el vuelo. $\mathrm{He}$ aquí la gran virtud de la dehesa tradicional: con escasas modificaciones 
técnicas y sin poner totalmente en peligro la riqueza ecológica del ecosistema es capaz de ofrecer, de manera simultánea, mayores rendimientos agrícolas, ganaderos y forestales ${ }^{7}$.

Las descripciones de mediados del siglo XIX coinciden en señalar la vigencia de tan extraordinaria adaptabilidad. Las hierbas de otoño e invierno (invernadero) y los pastos de primavera y verano (veranadero y agostadero) eran aprovechados por el ganado de labor del vecindario y por el ganado de renta de vecinos o forasteros. De octubre a enero, las encinas eran acotadas por las autoridades locales para dar prioridad en el aprovechamiento de la bellota al ganado de cerda (montanera). Comenzaba después la tala y la poda del arbolado (limpia), con una doble finalidad: asegurar la producción frutícola del año siguiente y obtener leña para los hogares de la colectividad. Paralelamente, en las épocas de sequía, las cabras aprovechaban a diente las puntas tiernas de los árboles (ramoneo). Entre los meses de abril y mayo, parte de las ramas extraídas durante el invierno eran transformadas en carbón vegetal (carboneo). En los montes que contenían formaciones de alcornoque, cada nueve o diez años se procedía a la extracción de la casca y de la cocha. La casca, con un alto contenido en tanino, se utilizaba como curtiente en la industria local del cuero. La corcha, además de los usos domésticos, participaba en los circuitos de exportación articulados en torno a la industria taponera. En los espacios más aptos para el cultivo, los vecinos sembraban cereales y los ganados apuraban los esquilmos (rastrojera) o la vegetación espontánea de las épocas de intermisión (barbechera). Por si fuera poco, los montes municipales ofrecían la posibilidad de completar el aprovechamiento estrictamente agro-silvo-pastoril con la apicultura, la caza, la pesca, la recolección de plantas medicinales o la extracción de piedras, arenas y arcillas ${ }^{8}$.

Las épocas y las condiciones de cada disfrute eran de sobra conocidas por todos los miembros de la comunidad. La existencia de códigos morales más o menos formales no garantizaba la ausencia de conflictos en el seno de la colectividad, pero, al menos, legitimaba las reclamaciones de los más desfavorecidos frente a los comportamientos insolidarios de vecinos y forasteros ${ }^{9}$. Tampoco aseguraba el reparto equitativo de los esquilmos del monte en una región donde la diferenciación interna había crecido de manera

\footnotetext{
7 Martin Galindo (1966), pp. 157-226, Elena, Bureau y López (1980), pp. 287-301, y Campos (1984), pp. 21-40.

${ }^{8}$ Propios, Arbitrios y Comunes (1835-1855).

" Una manifestación más de la «economía moral de la multitud» de la que habla Thompson (1984), pp. 62-134.
} 
palpable desde mediados del siglo XvI, pero sí avalaba con cierto grado de efectividad el mantenimiento de los usos que más contribuían a la formación del ingreso campesino: la alimentación de los animales de carga, la siembra de pequeñas parcelas de labor, el aprovisionamiento de materiales de construcción, la manutención de los cerdos, el abastecimiento de combustibles vegetales y la obtención de productos de la caza y de la pesca. La constatación de la pervivencia de este tipo de aprovechamientos a mediados del siglo XIX resulta de vital importancia para comprender la heterogeneidad que presentó en Extremadura el doble proceso de privatización y estatalización impulsado por la Ley General de Desamortización de 1 de mayo de 1855 .

\section{LA REDEFINICIÓN DE LOS DERECHOS DE PROPIEDAD $(1855-1875)$}

\subsection{De la nacionalización a la estatalización (1855-1865)}

A principios de febrero de 1855, Pascual Madoz exponía ante las Cortes Generales el proyecto que más tarde se convertiría en la Ley General de Desamortización. El borrador preveía, por una parte, la adjudicación en pública subasta de los bienes del clero aún no enajenados y, por otra, la nacionalización y venta de los bienes pertenecientes a los pueblos. Quedaba así trazada la culminación de un largo y discontinuo proceso privatizador en el que la intervención del Estado no siempre había sido determinante. Quizá, por eso, el nuevo proyecto, mucho más radical que todos los aprobados hasta entonces, contó desde el principio con la oposición de amplios sectores de la sociedad española.

En Extremadura, la protesta contra el proyecto estuvo protagonizada en un primer momento por las propias corporaciones locales. Pocas semanas después de conocer el plan, numerosos ayuntamientos comenzaron a enviar representaciones al Parlamento, exponiendo el tratamiento que, a su juicio, debían recibir los bienes de propios, arbitrios y comunes en la futura ley de desamortización. Los concejos más radicales solicitaron la total desestimación de la propuesta, argumentando que el patrimonio municipal era propiedad privada de los pueblos y que, por tanto, no podía ser enajenado por parte del Estado. Los menos enérgicos optaron por no discutir los principios jurídicos de la privatización y se limitaron a reclamar la excepción de las fincas necesarias para el sustento de la ganadería local. Otros muchos, 
los más numerosos, dejaron constancia de su oposición a la venta en pública subasta, pero propusieron el reparto a censo enfitéutico o reservativo entre todas las familias de cada pueblo ${ }^{10}$.

La reacción de las corporaciones extremeñas no fue expresada únicamente a través de la representación. En el transcurso de los debates parlamentarios, los diputados de la región trataron de conmover el ánimo de la Cámara con un discurso cargado de paternalismo hacia las capas más desfavorecidas de la sociedad. Frente a quienes opinaban que la escasa rentabilidad del patrimonio municipal era consecuencia de la pésima gestión consistorial, los representantes extremeños consideraban que era fruto de la moderación en el establecimiento de las rentas de adjudicación. En el caso de los terrenos comunales, la gratuidad de los aprovechamientos garantizaba el sustento de los vecinos más humildes. En el caso de los terrenos apropiados, la cesión de los disfrutes a bajo precio hacía posible el mantenimiento de la riqueza ganadera de la región. Desde esta perspectiva, la función social debía primar sobre la función fiscal y, consecuentemente, el Parlamento tenía que rechazar la propuesta de Pascual Madoz ${ }^{11}$.

Aunque los argumentos esgrimidos por los diputados de la región en nombre de los ayuntamientos podían estar plenamente justificados, dudo mucho que la principal preocupación de unos y otros fuera la suerte de los sectores más débiles del campesinado extremeño. No quiero decir con ello que la posible parcialidad de los representantes perjudicara a la gran mayoría de los representados. Digo, tan sólo, que los intereses realmente encarnados en la batalla legal contra el proyecto de desamortización no coincidían, en la práctica, con los de la comunidad a la que invocaban. Entre otras razones porque eran pocas las corporaciones que rechazaban la opción individualizadora en sí misma y porque, además, la historia de los bienes municipales extremeños no había estado precisamente exenta de procesos enajenadores.

A mi juicio, la protesta articulada a través de la vía parlamentaria no era una forma de resistencia contra la privatización, sino una forma de resistencia contra el modelo de privatización proyectado por el Ministerio de Hacienda. Según él, las ventas debían realizarse en subastas simultáneas que tendrían lugar, por una parte, en el pueblo donde radicara la finca y, por otra, en la capital del país. Ningún artículo preveía la preferencia de compra por parte de los antiguos usuarios del patrimonio municipal

${ }^{10}$ Diario de Sesiones (1880), pp. 2290, 2474, 2526, 2605, 2842, 3167, 3214, 3242, $3274,3504,3638,3781,3810,3837,3934$ y 3994.

${ }^{11}$ Diario de Sesiones (1880), pp. 3250-3294. 
y esto era lo que más incomodaba a las oligarquías locales extremeñas. De hecho, el caballo de batalla en todos los episodios enajenadores acaecidos con anterioridad había sido, precisamente, la cuestión de la vecindad; es decir, el derecho de los miembros de la comunidad a participar con prioridad en la privatización de los patrimonios municipales. La propuesta de Pascual Madoz dejaba, sin embargo, la puerta abierta a todo aquel que quisiera y pudiera intervenir en las subastas, muy particularmente a la floreciente burguesía madrileña. No es de extrañar, por tanto, que entre los motivos alegados por las instituciones locales de la región contra la futura ley de desamortización apareciera el temor a los «grandes capitalistas y banqueros que esquilmarían conjuntamente a pueblos y colonos» ${ }^{12}$.

El predominio de las aspiraciones oligárquicas en la protesta legal contra el proyecto privatizador no significaba inhibición de los más pobres en la defensa del patrimonio municipal. Como han puesto de relieve algunos autores, el uso desigual de los recursos concejiles y comunales, derivado de las diferencias en la riqueza individual y en el control institucional, no tenía por qué impedir la coincidencia de intereses entre los distintos usuarios. Los grandes ganaderos eran, sin lugar a dudas, los que obtenían una mayor cuota absoluta de producto en la explotación de los espacios municipales, pero, para los pequeños y medianos propietarios, no era de menor importancia relativa el aprovechamiento de los terrenos de propios, arbitrios y comunes ${ }^{13}$.

Otra cosa muy distinta es que la coincidencia de intereses implicara también coincidencia de acciones. En este sentido, lo que refleja la experiencia extremeña en la lucha contra la injerencia estatal es justamente la expresión de formas distintas de resistencia en función de las diferencias existentes entre los grupos implicados. Durante los primeros momentos la protesta parece estar dirigida por la oligarquía agraria a través de la vía legal: representaciones y discursos parlamentarios. No hay en ella una condena clara hacia la individualización de los bienes municipales, sino más bien hacia la inminente intervención del Estado en el proceso privatizador. Algún tiempo después, una vez sancionada la desamortización civil, la resistencia adquiere un matiz netamente distinto. Ante la evidencia de que los grandes potentados locales están dispuestos a participar activamente en las subastas, son los sectores más débiles de la sociedad los que toman las riendas de la protesta. Una protesta en la que se mezclan

\footnotetext{
12 Barrantes (1875), p. 487.

13 Sala (1997), p. 107.
} 
estrategias individuales de bajo riesgo (desplazamiento de linderos, entrada de ganado, robo de frutos, incendio, amenaza solapada, burla, difusión de rumores...) con tácticas colectivas previamente organizadas (invasiones de fincas, roturaciones masivas, derribos de cercas, algaradas populares, ataques contra la autoridad local, coacciones a los nuevos propietarios...). Habrá que esperar, sin embargo, a la caída de la Monarquía en 1868 para que este tipo de manifestaciones alcance en Extremadura un grado de propagación realmente importante.

Mientras tanto, aparecieron en escena los técnicos forestales españoles y, con ellos, los principios del forestalismo público europeo. Educados en las enseñanzas de la Academia de Tharandt (Sajonia), los introductores de la ciencia forestal en España difundieron con éxito los dos axiomas fundamentales de la dasonomía alemana: la necesidad de que el Estado asumiera la gestión del monte alto maderable y la conveniencia de que el cuerpo de ingenieros vigilara la explotación de la riqueza forestal ${ }^{14}$. Esta combinación de intervencionismo y conservacionismo caló pronto en la práctica política del país y llegó a incidir sustancialmente en el proceso de redefinición de los derechos de propiedad. Es más, buena parte de los debates que suscitó la apertura del proceso privatizador estuvo directamente relacionada con la dificultad para integrar en un mismo paquete legislativo liberalización y estatalización.

En un primer momento, la Ley de 1 de mayo de 1855 intentó solventar el asunto exceptuando de la desamortización los montes que el gobierno no considerara oportuno enajenar. Al mismo tiempo, en atención a las demandas de los pueblos, quedaron legalmente excluidos de la privatización los terrenos de aprovechamiento común y, meses más tarde, las dehesas destinadas al ganado de labor. Con ello y con la firme intención de redactar una ley hipotecaria que garantizara la posesión privada de los nuevos titulares quedó oficialmente abierto el proceso de redefinición de los derechos de propiedad en el ámbito de los patrimonios municipales. Desde entonces y hasta mediados de la década de los sesenta, la actividad legislativa se concentró fundamentalmente en precisar los criterios que debían cumplir para ser exceptuados los bienes inicialmente excluidos de la desamortización.

Por lo que respecta a los terrenos de aprovechamiento común, la legislación liberal dejó en manos de las corporaciones locales la elaboración

${ }_{14}$ Sobre la introducción del forestalismo público europeo en Espana, véanse Casals (1988), pp. 9-14, Jiménez Blanco (1991), pp. 251-252, y Gómez Mendoza (1992), pp. 19-49. 
de los expedientes de excepción y en manos de las delegaciones provinciales de Hacienda la resolución de los mismos. Los pueblos estaban obligados a presentar los títulos de propiedad de las fincas que desearan conservar y a demostrar que su disfrute había sido libre y gratuito desde 1835. Tales requisitos llegarían a ser muchas veces obstáculos insalvables para numerosas localidades extremeñas. En primer lugar, porque muy pocos pueblos podían demostrar la propiedad ejercida sobre el patrimonio municipal con algo más que con la invocación al uso o a la costumbre inmemorial. En segundo lugar, porque la propia multiplicidad productiva de la dehesa permitía particularizar el aprovechamiento de algunos disfrutes (pastos y labores) sin necesidad de descomunalizar el uso de otros muchos. Fuera como fuera, lo cierto es que la inobservancia de las formalidades exigidas por la legislación autorizaría al Ministerio de Hacienda a desaprobar muchos de los expedientes de excepción presentados por los ayuntamientos extremeños.

Algo más fácil resultaba, en teoría, conseguir la reserva de las dehesas destinadas al ganado de labor. En este caso, los pueblos no tenían que presentar los títulos de propiedad ni probar la gratuidad de los disfrutes; sólo debían demostrar, a través de los recuentos ganaderos, la necesidad real de los espacios solicitados. Este requisito permitía obtener la exclusión de superficies arrendadas con anterioridad, aunque limitaba las posibilidades de excepción a las extensiones que el Ministerio de Hacienda considerara convenientes. De hecho, muchos de los problemas que suscitó en Extremadura la exceptuación de las dehesas boyales estuvieron directamente relacionados con la disparidad de opiniones entre las delegaciones fiscales y las corporaciones locales en torno a la cantidad de tierra verdaderamente necesaria para el sostenimiento de la ganadería de labor.

En cuanto a los montes que el gobierno debía excluir de la desamortización, los criterios de excepción no fueron uniformes a lo largo de la segunda mitad del siglo XXX. Los primeros trabajos de clasificación estuvieron basados en el principio de la benéfica influencia de la superficie forestal sobre el entorno físico ${ }^{15}$. Bajo tal supuesto, los técnicos del ramo dejaron abierta una pequeña esperanza para el monte mediterráneo y, por tanto, para buena parte de las dehesas concejiles y comunales extremeñas. Así lo demostró la Clasificación General de 1859 al considerar exceptuado de la desamortización un porcentaje sustancial de la superficie municipal cubierta de encina, alcornoque, retama, jara y tomillo ${ }^{16}$. Muy pronto, sin

15 Véase, al respecto, Jiménez Blanco (1991), pp. 253-254.

16 Dirección General de Agricultura (1859). 
embargo, las necesidades financieras del Estado impusieron recortes significativos en las tendencias conservacionistas de los ingenieros españoles. Ante la voracidad del Ministerio de Hacienda, el gobierno dispuso en 1862 que tan sólo quedaran exceptuados de la enajenación los montes cuya especie dominante fuera pino, roble o haya y cuya superficie fuera, como mínimo, de 100 hectáreas. Este giro interpretativo suponía un duro golpe para la vegetación mediterránea y una notable merma para el conjunto de la riqueza forestal de los pueblos extremeños. Baste decir al respecto que, según el Catálogo de 1864, la superficie legalmente excluida de la enajenación por los nuevos criterios (especie dominante + extensión mínima) únicamente representaba el 7 por 100 de la extensión ocupada por el patrimonio municipal extremeño a la altura de $1855^{17}$.

Con las restricciones impuestas a la función protectora del monte, quedó teóricamente perfilada la redefinición de los derechos de propiedad. Por obra y gracia de la mixtificación liberal, los bienes de propios, arbitrios y comunes pasaron a ser definidos en la práctica jurídica como bienes de carácter público en el más estricto sentido de la palabra. Este cambio conceptual resultó determinante para legitimar la intervención del Estado en los patrimonios municipales excluidos de la desamortización. Dentro de ellos, la legislación estableció dos categorías distintas: montes exceptuados por razones ecológicas (montes de más de 100 hectáreas poblados de pino, roble o haya) y montes exceptuados por modalidad de disfrute (terrenos de aprovechamiento común y dehesas boyales). La competencia administrativa de unos y otros quedó en manos de los ayuntamientos y la competencia facultativa (conservación y aprovechamiento) pasó a depender directamente de los ingenieros forestales del Ministerio de Fomento. No obstante, en el caso de los terrenos de aprovechamiento común y de las dehesas boyales, fue el Ministerio de Hacienda el organismo encargado de la resolución de los expedientes de excepción. Por su parte, los montes no excluidos de la desamortización pasaron a ser considerados como bienes públicos enajenables y, por tanto, sujetos a la venta. Una vez subastados y rematados en el mejor postor, los nuevos propietarios tenían la obligación de inscribirlos en el flamante Registro de la Propiedad. En tanto no fueran enajenados, el control facultativo de tales terrenos, al igual que el de los montes exceptuados, debía correr a cargo de los técnicos del Ministerio de Fomento, una solución temporal que no dejaría de provocar conflictos

${ }^{17}$ Dirección General de Agricultura (1864). 
de competencia a lo largo del último tercio del siglo XIX en todo el territorio nacional ${ }^{18}$.

\subsection{De la privatización indiscriminada a la resistencia generalizada (1865-1875)}

El Real Decreto de 17 de mayo de 1865 aprobó el reglamento para la ejecución de los aprovechamientos forestales en los montes públicos españoles. Según él, los ingenieros del Ministerio de Fomento destinados en cada provincia debían estudiar las propuestas de explotación redactadas por los ayuntamientos y elaborar, a partir de ellas, un plan provisional de aprovechamientos en el que constara la producción prevista para el año siguiente y la producción efectivamente realizada durante el año anterior. El objetivo fundamental no era sólo adecuar los usos tradicionales del monte a los principios de la dasonomía, sino también convertir los disfrutes libres y gratuitos en aprovechamientos restringidos y onerosos. Con ello, el Estado pretendía regularizar la recaudación de impuestos sobre la producción de los montes públicos españoles al objeto de costear la propia administración forestal. Otra cosa es que los pueblos estuvieran dispuestos a renunciar sin más a los derechos consuetudinarios de uso, máxime, cuando las ventas del antiguo patrimonio municipal habían alcanzado, a la altura de 1865 , volúmenes verdaderamente importantes ${ }^{19}$.

Para algunos autores, la etapa abierta tras la reglamentación de los aprovechamientos fue una de las más terribles de la historia forestal española en términos ecológicos ${ }^{20}$. Las tendencias privatizadoras se unieron a la revolución democrática y a la falta de liquidez del Tesoro para dar paso a un proceso de sobreexplotación en el que el monte público español fue concebido como una mera fuente de ingresos ${ }^{21}$. Extremadura no quedó al margen de semejante devastación, como ponen de manifiesto las memorias redactadas por los ingenieros de Cáceres y Badajoz en los planes provisionales de aprovechamientos. Según ellos, las delegaciones provinciales de Hacienda, desoyendo las recomendaciones dasonómicas y las propias

\footnotetext{
${ }^{18}$ Véanse, entre otros, Moreno (1992), pp. 344-358, Manuel (1994), pp. $343-348$ y Sala (1998), pp. 177-180.

19 Para la provincia de Cáceres, puede verse García Pérez (1994), pp. 66-75.

${ }^{20}$ Bauer (1980), p. 80.

${ }^{21}$ Véase Jiménez Blanco (1991), pp. 257-258.
} 
disposiciones desamortizadoras, enajenaron durante este periodo numerosos montes hasta entonces legalmente exceptuados ${ }^{22}$.

No fue, sin embargo, la voracidad del departamento fiscal la única responsable de los atentados cometidos contra la riqueza forestal de los municipios extremeños. Hay que tener en cuenta que, para proceder a la venta de una finca nacionalizada, debía ser un particular el que previamente reclamara la celebración de la subasta. En este sentido, las delegaciones provinciales de Hacienda actuaron a veces como instrumentos al servicio de las tendencias privatizadoras existentes en el seno de las propias comunidades rurales. Por otra parte, es preciso señalar que, junto a la agresividad compradora de las oligarquías agrarias de la región, fueron los sectores más débiles del campesinado los que protagonizaron, en múltiples ocasiones, fenómenos de explotación fraudulenta calificados como «acciones delictivas» por la legislación liberal y por la práctica forestal. En algunos casos se trataba simplemente de formas de resistencia tendentes al mantenimiento de las prácticas tradicionales. En otros, sin embargo, la desarticulación legal de los usos colectivos y la reducción de los espacios comunales hicieron concentrar la presión de los antiguos usuarios sobre los montes no enajenados. Así lo ponen de manifiesto las talas indiscriminadas, los incendios intencionados, las roturaciones arbitrarias y las pasturas descontroladas que con tanta frecuencia recogieron las estadísticas forestales de la época ${ }^{23}$.

Todo parece indicar que la coincidencia de intereses en la defensa de los aprovechamientos colectivos comenzó a resquebrajarse durante el periodo comprendido entre 1865 y 1875 . A ello contribuyó el hecho de que fueran los potentados locales los más rápidos en solicitar la enajenación de los montes nacionalizados una vez aprobada la Ley General de Desamortización. Asimismo, el clima de libertades abierto tras el triunfo de la revolución de 1868 jugó un papel determinante en la radicalización de las posturas. No en vano, las fuentes de la época contienen numerosos ejemplos en los que, junto a la creciente manifestación de acciones «delictivas» concentradas en la superficie forestal exceptuada, aparecen documentados ataques, individuales o colectivos, contra los montes enajenados, contra los nuevos propietarios y contra los ayuntamientos enajenadores. Es más, fue entonces cuando se asistió en Extremadura al nacimiento de un notable movimiento asociativo que mantuvo estrechas relaciones con

\footnotetext{
${ }^{22}$ Planes de Aprovechamientos (1873-1925: Memorias de 1873, 1874, 1875 y 1876).

${ }^{23}$ Dirección General de Agricultura (1866-1887).
} 
la I Internacional y cuando los levantamientos populares en el campo adquirieron una virulencia pocas veces constatada en estas latitudes: incendios en dehesas boyales, talas de arbolado, robos masivos de frutos, invasiones de fincas, derribos de cercas, agresiones físicas a las autoridades locales, introducción de ganados en terrenos privatizados, coacciones a los grandes propietarios, repartos equitativos de antiguos montes municipales en favor de los vecinos más pobres... ${ }^{24}$.

La generalizada participación de los desposeídos en este tipo de manifestaciones restó protagonismo a la batalla legal contra la privatización, pero no supuso la total desaparición de esa otra forma de resistencia. Los ayuntamientos de la región, en nombre de las comunidades rurales, continuaron ejerciendo la protesta a través de las representaciones dirigidas al Parlamento o a través de los discursos leídos en las Cortes por los diputados extremeños. En ambos casos, las reclamaciones giraron en torno a la anulación de las enajenaciones realizadas, a la paralización total o parcial del proceso privatizador y a la adjudicación gratuita de suertes para labor en antiguos montes de propios, arbitrios y comunes. Hubo, sin embargo, un tema estrella que consiguió atraer la atención de la mayor parte de los implicados en la lucha contra la desarticulación de los usos colectivos: la resolución favorable de los expedientes tramitados para obtener la excepción de terrenos de aprovechamiento común y dehesas boyales ${ }^{25}$.

A juzgar por las investigaciones realizadas hasta el momento, fueron muchas las corporaciones locales que pidieron la exclusión de espacios comunales, pero muy pocas los que obtuvieron la superficie o la finca inicialmente solicitada. Los motivos alegados por los ayuntamientos estuvieron presididos por la necesidad de alimentar a los animales de labor y por la tradicional gratuidad de los aprovechamientos realizados en las fincas requeridas. Las autoridades fiscales, sin embargo, encontraron casi siempre razones de peso para desestimar las propuestas. Muchas veces fue el desajuste entre la superficie solicitada y el tamaño de la cabaña ganadera local el principal argumento esgrimido por el Ministerio de Hacienda para limitar o para rechazar la petición. Otras veces, la denegación estuvo marcada por la incompatibilidad entre los montes demandados por modalidad de disfrute (terrenos de aprovechamiento común y dehesas

${ }^{24}$ García Pérez, Sánchez Marroyo y Merinero (1985), pp. 891-894, y Sánchez Marroyo (1992), pp. 35-156.

${ }^{25}$ Diario de Sesiones (1870), pp. 566, 816, 817, 1553, 2534, 2535, 2440, 3420, 3757, $5083,6116,7216$ y 8248 y (1874), pp. $391,561,562,575,668,682,796,943,1023$, $1106,1109,1949$ y 2011. 
boyales) y los montes exceptuados por razones ecológicas (especie dominante + extensión mínima). No obstante, los pretextos más utilizados para rechazar las excepciones solicitadas fueron, por una parte, la inexistencia de títulos de propiedad y, por otra, el incumplimiento de la gratuidad de todos los aprovechamientos ${ }^{26}$.

Como manifesté más arriba, resultaba difícil para los pueblos extremeños demostrar documentalmente los derechos que concurrían en la explotación comunal de los patrimonios municipales. El uso y la costumbre eran los únicos títulos que tradicionalmente habían garantizado la posesión colectiva hasta que el derecho liberal inventó el Registro de la Propiedad. Además, ¿qué sentido tenía exigir documentos demostrativos de algo que la propia legislación desamortizadora negaba al convertir los bienes de propios, arbitrios y comunes en bienes de carácter público? Por otra parte, los gobiernos españoles de la época incurrían en una grave contradicción cuando, junto a la cuestión de los títulos, imponían la gratuidad como condición sine qua non. Contradicción, porque dejaban en manos de las haciendas locales la financiación de los servicios municipales (administración, educación, salud, obras públicas...) sin dotarlas para ello de los recursos necesarios ${ }^{27}$.

En cualquier caso, los pueblos extremeños estuvieron a la altura de las circunstancias y descubrieron la manera de evitar la enajenación. Dada la extensión de la región y la escasez de personal, no fue difícil ocultar la existencia de ciertas fincas municipales. Así lo ponen de manifiesto los ingenieros destinados en Extremadura cuando documentan la inserción de nuevos montes en los planes anuales de aprovechamientos ${ }^{28}$. Qué duda cabe que fue ésta otra forma de resistencia en la que las propias corporaciones locales jugaron un papel fundamental. Pero icuidado!, no todos los ayuntamientos mantuvieron siempre una actitud tan combativa. Algunos municipios, después de solicitar y conseguir la excepción de terrenos comunales, pidieron a las delegaciones de Hacienda la enajenación de los mismos ${ }^{29}$. En este sentido, insisto, las instituciones encargadas de dirigir el proceso desamortizador no fueron tanto entidades autónomas capaces de imponer la privatización, como instrumentos canalizadores de las distintas tendencias (individualizadoras y comunalizadoras) existentes en el mundo rural.

\footnotetext{
${ }^{26}$ García Pérez (1986), pp. 206-216.

27 Véase, al respecto, García García y Comín (1995), pp. 90-101.

${ }^{28}$ Planes de Aprovechamientos (1873-1925).

29 Planes de Aprovechamientos (1873-1925: Memorias de 1874, 1875 y 1876).
} 


\section{LA INTERVENCIÓN DEL ESTADO EN LOS MONTES PÚBLICOS EXTREMEÑOS (1875-1924)}

\subsection{Ciencia forestal y repulsa popular (1875-1900)}

Desde principios del último cuarto del siglo XIX, el proceso privatizador abierto tras la publicación de la Ley de 1 de mayo de 1855 adquirió un nuevo rumbo. Comenzaron a remitir las enajenaciones respecto a la etapa anterior $y$, en su lugar, empezaron a dominar la escena interventora los trabajos técnicos tendentes a la regularización de la producción forestal. La restauración monárquica y la consolidación de un régimen oligárquico caracterizado por el control del sistema electoral y la contención de la discrepancia aseguró a los potentados locales la propiedad sobre los terrenos desamortizados y la potestad sobre los mercados de trabajo. La creciente militarización de los campos españoles como consecuencia del reforzamiento de la guardería rural a través de la guardia civil hizo reducir la protesta popular tumultuaria. El asociacionismo del Sexenio Democrático consiguió sobrevivir durante algún tiempo en la clandestinidad, pero la represión sancionada por el régimen y la consecuente desmovilización política impidieron la emergencia de nuevos movimientos organizados. En su defecto, la protesta contra la desamortización continuó ejerciéndose mediante estrategias de bajo riesgo, ahora especialmente latentes en los montes gestionados por los ingenieros forestales.

En Extremadura, una de las regiones donde el funcionamiento del caciquismo alcanzó mayores cotas de eficacia, la remisión de las enajenaciones de superficie a partir de 1875 estuvo acompañada de un incremento sustancial en las ventas de arbolado. Así lo denunciaron constantemente los técnicos del Ministerio de Fomento en los planes de aprovechamientos forestales. Se trataba, generalmente, de refundiciones de dominios en fincas donde, hasta entonces, el derecho de uso había estado compartido entre el vecindario de una determinada localidad y uno o varios particulares. Los ingenieros reaccionaron ante tales manifestaciones, culpando a los pueblos extremeños de pasividad. En su opinión, las corporaciones locales no presentaban pleitos contra los desgajamientos del patrimonio municipal, unas veces, porque no confiaban en los resultados $y$, otras, porque estaban dirigidas por caciques interesados en comprar a través de «resortes bien conocidos de todos y bastante públicos y notorios» ${ }^{30}$.

\footnotetext{
${ }^{30}$ Planes de Aprovechamientos (1873-1925: Memorias de 1880-1890).
} 
No niego la veracidad de los argumentos esgrimidos por los técnicos para explicar las ventas descontroladas de arbolado acaecidas durante el último cuarto del siglo XIX. Dudo, sin embargo, que fuera la pasividad de los pueblos extremeños la característica más destacable de la época. Por el contrario, creo que la generalizada oposición que encontraron los ingenieros destinados en Extremadura a la hora de intentar «racionalizar» la explotación de los antiguos montes de propios, arbitrios y comunes revelaba con claridad que, pese a las tendencias individualizadoras, los antiguos usuarios del patrimonio rústico municipal no estaban dispuestos a perder totalmente los derechos comunales de uso. Que la resistencia no estuviera presidida por la violencia organizada como en años anteriores no significaba, ni mucho menos, que las comunidades rurales hubieran abdicado finalmente ante el proceso privatizador ${ }^{31}$.

Una de las prácticas más utilizadas por los pueblos extremeños para impedir la inspección técnica de los aprovechamientos forestales fue la no redacción de las propuestas que debían remitir anualmente a los ingenieros. La indiferencia de las corporaciones locales ante los requerimientos oficiales ocupó siempre un lugar primordial entre las razones ofrecidas por los técnicos del servicio para justificar las grandes diferencias existentes entre las previsiones y las producciones reales (Cuadro 4, p. 42). En primer lugar, porque, dada la supuesta apatía de los ayuntamientos, los planes de aprovechamientos, al menos hasta principios del siglo $\mathrm{XX}$, no fueron más que relaciones «ilusorias», establecidas en base a los cálculos dasonómicos de los propios ingenieros. En segundo lugar, porque, incluso cuando los pueblos enviaron sus propuestas, la ejecución de las mismas pocas veces se atuvo a los pliegos de condiciones redactados por los técnicos del ramo.

Otra de las manifestaciones que adquirió la resistencia contra la intervención estatal fue la negativa de los pueblos a pagar los impuestos establecidos sobre el uso de los terrenos aún no enajenados. Desde 1877, el 10 por 100 del valor total de la producción de los montes públicos españoles tenía que ser destinado a las tareas de repoblación y mejora. En principio, nadie podía realizar un determinado disfrute sin estar en posesión de la carta que certificaba el pago de tal impuesto. De hecho, los encargados de la vigilancia estaban obligados a impedir la ejecución de cualquier tipo de aprovechamiento que no estuviera avalado por la firma del ingeniero $\mathrm{y}$, en su defecto, a imponer elevadas sanciones a quienes

${ }^{31}$ Véase, al respecto, Sala (1997), pp. 105-124. 
persistieran en hacerlo de manera fraudulenta. Las noticias recogidas en los planes forestales confirman, sin embargo, no sólo que la mayor parte de los interesados incumplía los requerimientos tributarios, sino que, además, eran realmente pocas las multas que llegaban a ser pagadas por los infractores.

Únicamente, a partir de los años noventa, empezó a regularizarse en Extremadura el pago anual del 10 por 100. Hasta entonces, los ingenieros tuvieron que hacer frente a innumerables desafíos por parte de las comunidades rurales. La legislación liberal intentó, desde 1865, incrementar el valor de los productos subastados y limitar el de los productos disfrutados gratuitamente. Ésta era una manera de elevar los rendimientos en metálico de los montes públicos y de aumentar la recaudación de los impuestos sobre la producción forestal. En la práctica, sin embargo, la imposición de la subastas no fue tarea fácil. A pesar de las continuas rebajas que tuvieron que hacer los técnicos forestales en los precios de salida para conseguir un mínimo de licitadores, los pueblos extremeños encontraron en la deserción previamente pactada uno de los métodos más útiles para continuar explotando los montes municipales a espaldas de la Administración. La no presentación de postores en las subastas celebradas anualmente para proceder a la adjudicación de los pastos o de los frutos estuvo siempre a la orden del día en las memorias redactadas por los ingenieros forestales. Sólo cuando, a partir de la última década del siglo XIX, las autoridades del Ministerio de Fomento reconocieron el derecho de los rematantes a disfrutar por tres y cuatro años los invernaderos y las montaneras de manera conjunta las subastas empezaron a gozar de cierta aceptación entre los usuarios de los montes aún no enajenados ${ }^{32}$.

Pese a todo, el sistema de adjudicación por subasta pocas veces aseguró en tierras extremeñas el sometimiento de los arrendatarios a los requisitos técnicos establecidos. Los reiterados intentos por limitar la entrada de ganado en los montes del patrimonio municipal no pudieron evitar la generalizada costumbre de introducir un número de cabezas mayor al contratado durante la celebración de las licitaciones. Esta otra forma de resistencia contra los principios de la ciencia forestal adquirió especial relevancia en lo tocante al ganado caprino, enemigo declarado del monte según los ingenieros de la época. Los pueblos extremeños hicieron oídos sordos a las recomendaciones de los técnicos y ampliaron continuamente el número

${ }^{32}$ Para algunos autores, la imposición de las subastas en la adjudicación de los aprovechamientos forestales fue una de las principales vías de penetración y expansión de las relaciones de mercado en el mundo rural. Ver Jiménez Blanco (1991), pp. 272-278. 
de cabras introducidas en los montes todavía no enajenados. En este caso, el mercado resultó ser mucho más fuerte que el Estado. Quizá porque el problema nunca estuvo en el supuesto rechazo de las comunidades tradicionales al juego de la oferta y la demanda sino en la resistencia del mundo rural a la intermediación de la Administración central.

De la dificultad para imponer principios maximizadores llegaron a ser conscientes los ingenieros destinados en Extremadura a los pocos años de comenzar a funcionar el servicio forestal. Iniciados en la dasonomía germánica, claramente influida por el contacto directo con el monte centroeuropeo, los recién llegados tuvieron que superar en primer lugar la desilusión ante un monte mediterráneo completamente diferente. En la fase de descubrimiento, las tradicionales prácticas multiuso de la dehesa revelaron las disparidades existentes entre la ciencia y la experiencia. Fue entonces cuando los ingenieros comenzaron a claudicar ante ciertas evidencias, entre ellas, la posibilidad de labrar parte de la superficie forestal. De hecho, los técnicos destinados en el suroeste peninsular empezaron desacreditando la realización de roturas en los montes del patrimonio municipal y terminaron defendiendo ante las máximas autoridades forestales del país la conveniencia de este tipo de aprovechamientos. Fue entonces cuando las rozas y labores desarrolladas tradicionalmente en las superficies adehesadas extremeñas dejaron de ser consideradas «atrocidades» para convertirse en «mejoras» ${ }^{33}$.

Algo parecido sucedió con la leña y con la caza. En ambos casos, los ingenieros intentaron, desde el principio, imponer el sistema de subasta. No obstante, pese a los requerimientos del Estado, los técnicos provinciales acabaron reconociendo la imposibilidad de regularizar tales disfrutes. Quedó así expresada la necesidad de conciliar las aspiraciones del forestalismo y los intereses reales del mundo rural. $Y$ es que, ante la imposibilidad de impedir la realización de ciertas prácticas locales, los ingenieros no tuvieron más remedio que admitirlas para conseguir un mínimo de aceptación entre los pueblos y para evitar males mayores: ataques indiscriminados a la superficie forestal en respuesta a la prohibición ${ }^{34}$.

El paulatino acercamiento entre ingenieros y vecinos a lo largo del último tercio del siglo $\mathrm{XX}$ no debe ser interpretado, sin embargo, como la derrota definitiva de las tendencias privatizadoras frente a las tendencias comunalizadoras. En primer lugar, porque, poco a poco, la administración

${ }^{33}$ Planes de Aprovechamientos (1873-1925: Memorias de 1875-1880).

${ }^{34}$ Véase, al respecto, la tesis doctoral de Manuel (1994), pp. 365-366. 
forestal consiguió imponer el sistema de subastas en algunos aprovechamientos hasta entonces adjudicados gratuitamente. En segundo lugar, porque, a veces, las demandas del mercado resultaron ser más importantes para las propias comunidades rurales que las demandas del Estado. En tercer lugar, porque, al margen de la intervención técnica en los montes no enajenados, los espacios forestales tradicionalmente destinados al uso colectivo quedaron drásticamente reducidos como consecuencia del proceso desamortizador. Según mis cálculos, los montes transferidos a manos de particulares entre 1855 y 1900 representaron nada menos que el 75 por 100 de la superficie forestal ocupada por el patrimonio municipal a mediados del siglo XIX (Cuadro 2). Más que hablar de victoria de la comunidad rural frente el avance del individualismo agrario habría que hablar, por tanto, de solución de compromiso ante el embate del intervencionismo estatal.

\section{CUADRO 2}

Superficie Forestal de los Patrimonios Municipales Extremeños en 1900

\begin{tabular}{|c|c|c|c|c|c|c|}
\hline \multirow{2}{*}{$\begin{array}{c}\text { Especie } \\
\text { Dominante }\end{array}$} & \multicolumn{2}{|c|}{ Badajoz } & \multicolumn{2}{|c|}{ Cáceres } & \multicolumn{2}{|c|}{ Extremadura } \\
\hline & Hectáreas & Porcentaje & Hectáreas & Porcentaje & Hectáreas & Porcentaje \\
\hline Encina .. & 72.694 & 62,7 & 43.632 & 28,4 & 116.326 & 43,1 \\
\hline Alcornoque.............. & 335 & 0,3 & 4.907 & 3,2 & 5.242 & 1,9 \\
\hline 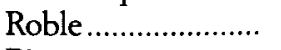 & 32.711 & 28,2 & 53.087 & 34,5 & 85.798 & 31,8 \\
\hline Pino & 0 & 0,0 & 5.332 & 3,5 & 5.332 & 2,0 \\
\hline Otros ......................... & 0 & 0,0 & 457 & 0,3 & 457 & 0,2 \\
\hline Matorral ...................... & 5.946 & 5,1 & 39.654 & 25,8 & 45.600 & 16,9 \\
\hline Raso............................ & 4.008 & 3,5 & 5.107 & 3,3 & 9.115 & 3,4 \\
\hline Desconocido ............ & 250 & 0,2 & 1.544 & 1,0 & 1.794 & 0,7 \\
\hline Total......................... & 115.944 & 100,0 & 153.720 & 100,0 & 269.664 & 100,0 \\
\hline
\end{tabular}

FUENTE: Dirección General de Propiedades (1897), Dirección General de Agricultura (1901) y Planes de Aprovechamientos (1873-1925: Estados de 1925).

\subsection{La otra cara de la dehesa extremeña (1900-1924)}

A finales del siglo xIx el gobierno introdujo una importante modificación en los criterios de excepción. La Ley de Presupuestos de 1896, además de sancionar la reserva de los terrenos de aprovechamiento común y de 
las dehesas boyales, consideró excluidos de la enajenación los montes que conviniera mantener poblados o repoblar de vegetación arbórea para garantizar la salubridad pública, el régimen regular de las aguas o la fertilidad de los suelos. El principio utilizado hasta entonces para determinar legalmente qué montes eran o no enajenables (especie dominante + extensión mínima) fue así sustituido por un criterio bastante más amplio en el que, no sólo aparecía recogida la función protectora de las superficies forestales, sino también la necesidad de conservar espacios desarbolados susceptibles de repoblación. Bajo la denominación genérica de «montes de utilidad pública», los terrenos catalogados como inalienables en virtud del nuevo criterio quedaron en manos de los ingenieros del Ministerio de Fomento. $\mathrm{El}$ resto (terrenos de aprovechamiento común, dehesas boyales y montes enajenables aún no vendidos) pasó a ser directamente gestionado por un nuevo cuerpo de ingenieros dependiente del Ministerio de Hacienda ${ }^{35}$.

La herramienta con la que contaban los técnicos de uno y otro ministerio para llevar a cabo el control facultativo de los montes a su cargo era la misma: elaboración anual de un plan de aprovechamientos forestales. Todavía, sin embargo, no han sido hallados los escritos redactados por los ingenieros del Ministerio de Hacienda durante las dos primeras décadas del siglo $\mathrm{xx}$. Las únicas noticias que existen, al respecto, proceden de los boletines oficiales de cada provincia. En ellos aparecían reflejadas las previsiones anuales de producción, pero no las circunstancias que rodeaban la ejecución de los aprovechamientos. Estos detalles habrían sido fundamentales para conocer el grado de aplicación de los planes y la evolución de las privatizaciones en la etapa final de la desamortización, ya que, según mis cálculos, a la altura de 1925, la superficie forestal ocupada por los patrimonios municipales extremeños había descendido en algo menos de 16.000 hectáreas respecto al año 1900 (Cuadro 3). Es indudable que el ímpetu comprador había ido remitiendo desde 1875 , entre otras razones, porque los montes más apetecibles habían sido ya enajenados. No obstante, los datos disponibles invitan a considerar que todavía a principios del siglo $\mathrm{xX}$ los sectores tendentes a la privatización continuaban ejerciendo su derecho legal a adquirir la propiedad de los antiguos terrenos de propios, arbitrios y comunes ${ }^{36}$.

Este derecho quedó herido de muerte en 1917 cuando el gobierno ordenó la redacción de un nuevo reglamento para la administración de

${ }^{35}$ Los montes de Fomento quedaron catalogados en Dirección General de Agricultura (1901) y los de Hacienda en Dirección General de Propiedades (1897).

${ }^{36}$ Así ocurrió en otras zonas del país según cita Jiménez Blanco (1991), p. 260. 


\section{CUADRO 3}

Superficie Forestal de los Patrimonios Municipales Extremeños en 1925

\begin{tabular}{|c|c|c|c|c|c|c|}
\hline \multirow{2}{*}{$\begin{array}{c}\text { Especie } \\
\text { Dominante }\end{array}$} & \multicolumn{2}{|c|}{ Badajoz } & \multicolumn{2}{|c|}{ Cáceres } & \multicolumn{2}{|c|}{ Extremadura } \\
\hline & Hectáreas & Porcentaje & Hectareas & Porcentaje & Hectáreas & Porcentaje \\
\hline Encina .......... & 69.633 & 65,9 & 40.795 & 27,6 & 110.428 & 43,5 \\
\hline Alcornoque....... & 335 & 0,3 & 4.907 & 3,3 & 5.242 & 2,1 \\
\hline 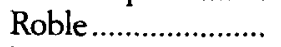 & 26.488 & 25,1 & 51.888 & 35,0 & 78.376 & 30,8 \\
\hline Pino........................ & 0 & 0,0 & 4.978 & 3,4 & 4.978 & 2,0 \\
\hline 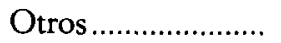 & 0 & 0,0 & 457 & 0,3 & 457 & 0,2 \\
\hline Matorral .................... & 5.763 & 5,4 & 39.654 & 26,8 & 45.417 & 17,9 \\
\hline Raso............................. & 3.279 & 3,1 & 4.657 & 3,1 & 7.936 & 3,1 \\
\hline 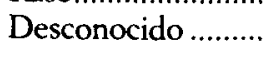 & 250 & 0,2 & 764 & 0,5 & 1.014 & 0,4 \\
\hline Total ............................ & 105.748 & 100,0 & 148.100 & 100,0 & 253.848 & 100,0 \\
\hline
\end{tabular}

FUENTE: Planes de Aprovechamientos (1873-1925: Estados de 1925).

las haciendas locales, suspendiendo al efecto la legislación desamortizadora. En 1921, las superficies a cargo del Ministerio de Hacienda pasaron nuevamente a depender del Ministerio de Fomento. Tres años más tarde, la dictadura de Primo de Rivera devolvió a las corporaciones locales la gestión de todos los montes municipales, enajenables y no enajenables. Finalmente, el Estatuto Municipal de 8 de marzo de 1924 dictó el acta de defunción del proceso abierto tras la publicación de la Ley de 1 de mayo de 1855 al derogar las disposiciones desamortizadoras y al confirmar la potestad de los ayuntamientos en todo lo referente a la gestión de los montes de propios, arbitrios y comunes. Quedaron así cerradas las dos vías de actuación estatal en los patrimonios municipales: la venta en pública subasta de la propiedad y la intervención técnica de la producción.

Hasta entonces y desde principios de siglo, la información procedente del Ministerio de Fomento revela un mayor acercamiento entre los principios de los técnicos destinados en Extremadura y los intereses de los pueblos extremeños. Por una parte, disminuyeron significativamente las distancias que separaban el valor de la producción prevista en los planes forestales y el valor de la producción efectivamente realizada en los montes no enajenados (Cuadro 4). Por otra, pese al avance de los disfrutes efectuados en subasta pública (ordinarios) respecto a los aprovechamientos realizados gratuitamente (vecinales), las memorias redactadas por los inge- 


\section{CUADRO 4}

Producción de los Montes Municipales Extremeños (Miles de Pesetas Constantes de 1913)

\begin{tabular}{|c|c|c|c|c|}
\hline Trienios & $\begin{array}{c}\text { Producción } \\
\text { prevista } \\
\text { (I) }\end{array}$ & $\begin{array}{l}\text { Producción } \\
\text { realizada } \\
\text { (II) }\end{array}$ & $\begin{array}{c}\text { Diferencia } \\
\quad(I-I I)\end{array}$ & $\begin{array}{c}\text { Porcentaje } \\
(I-I I / I) \times 100\end{array}$ \\
\hline $1875-1877 \ldots \ldots \ldots \ldots \ldots$ & 1.123 & 324 & 799 & 71,1 \\
\hline $1895-1897 \ldots \ldots \ldots \ldots \ldots$ & 1.548 & 1.278 & 270 & 17,4 \\
\hline $1923-1925 \ldots \ldots \ldots \ldots \ldots \ldots$ & 1.106 & 1.073 & 33 & 2,9 \\
\hline
\end{tabular}

FuENTE: Planes de Aprovechamientos (1873-1925) y Dirección General de Agricultura (1926-1928).

nieros durante el primer cuarto de siglo denotan una relajación de los conflictos suscitados en torno a la explotación anual de los montes municipales. A ello contribuyeron, sin duda, el contacto directo de los técnicos con la realidad regional y el afianzamiento de una nueva economía forestal basada en la creciente valoración de los recursos tradicionales del monte mediterráneo ${ }^{37}$.

Los síntomas más claros de acercamiento estuvieron relacionados con la aceptación de prácticas hasta entonces negativamente valoradas por la dasonomía: aumento de la carga ganadera e incremento de la superficie cultivada. En el primer caso, pese a las continuas advertencias de la administración forestal, los ingenieros acabaron reconociendo la importancia económica de los aprovechamientos pascícolas en los patrimonios municipales extremeños y consintieron año tras año la ampliación de la cabaña ganadera en las superficies intervenidas. Es más, contra todo principio científico, algunos técnicos llegaron a mostrarse decididamente partidarios de ampliar el número de cabras en los antiguos montes de propios, arbitrios y comunes. En el caso de los cultivos, fueron las propias autoridades del país las que regularon e, incluso, impulsaron en ciertos momentos el incremento de la superficie dedicada a la agricultura. Así lo hizo, por ejemplo, el Ministerio de Hacienda en 1915 cuando instó a sus ingenieros a estudiar qué montes podían ser objeto de roturación, roza y siembra. No fue ésta, la actitud del Ministerio de Fomento, pero sí la de los técnicos a su cargo, como ponen de manifiesto las frecuentes inclusiones de nuevas roturaciones

37 Véase Gómez Mendoza (1992), pp. 97-114. 
en los planes redactados para responder a las peticiones cursadas por los pueblos extremeños ${ }^{38}$.

La importancia que adquirieron tales solicitudes estuvo en consonancia con la trayectoria seguida por el sector primario regional tras la crisis agropecuaria de finales del Ochocientos. La reacción ante la caída finisecular estuvo caracterizada en Extremadura por un notable incremento de la superficie cultivada en favor de cereales y leguminosas, pero no, como en otros lugares de la península, por modificaciones sustanciales en el uso del suelo. De hecho, la ampliación de los cultivos no supuso la reducción de la cabaña ganadera. Por el contrario, el crecimiento de la demanda nacional e internacional de productos cárnicos fue aprovechado por los extremeños para continuar abundando en la especialización ganadera del suroeste peninsular. En términos relativos, la producción ovina, porcina y caprina de la región creció más deprisa que la producción agrícola durante los veinticinco primeros años del siglo xx. Esta expansión no fue el resultado de importantes transformaciones técnicas, sino de los esfuerzos por aprovechar al máximo las potencialidades de la dehesa. Al fin y al cabo, la ampliación de la superficie cultivada no tenía por qué implicar una reducción de los recursos disponibles para el abastecimiento de la ganadería, sino, más bien, una mejora cualitativa de los mismos en detrimento del monte impenetrable ${ }^{39}$.

Todo parece indicar que, en este proceso de expansión sin innovación, los montes enajenados jugaron un papel fundamental. Pero también hay indicios suficientes para pensar que la evolución de la superficie no privatizada quedó igualmente marcada por el singular dinamismo de la dehesa. Esta singularidad fue la que terminaron aceptando los ingenieros destinados en Extremadura cuando dejaron de aplicar los principios de la ciencia forestal germánica, difícilmente materializables en el suroeste peninsular, y trataron de complementar la ampliación de los cultivos con el aumento de la carga ganadera. El abandono de las recomendaciones dirigidas a incrementar la producción de maderas y leñas o la condescendencia mostrada por los técnicos hacia actividades como la caza, la recolección de plantas y la extracción de piedras o arenas, reforzaron aún más el acercamiento. Como contrapartida, la administración forestal logró regularizar el pago de los impuestos sobre la producción, reducir el peso relativo de los dis-

${ }^{38}$ Planes de Aprovechamientos (1873-1925: Estados de 1900-1925).

${ }_{39}$ Un análisis profundo de la evolución del sector agrario extremeño durante las primeras décadas del siglo xx puede verse en Zapata (1985). 
frutes gratuitos e imponer de manera creciente el sistema de subasta en la cesión de los aprovechamientos más importantes (Cuadro 5).

\author{
CUADRO 5 \\ Usos Forestales en los Montes Públicos Extremeños \\ (Medias Trienales)
}

\begin{tabular}{cccccccc}
\hline \multirow{2}{*}{ Trienios } & \multicolumn{3}{c}{ Miles de pesetas constantes de 1913 } & \multicolumn{3}{c}{ Porcentajes sobre el total trienal } \\
\cline { 2 - 7 } & Ordinario & Vecinal & Extraordinario & Ordinario & Vecinal & Extraordinario \\
\hline $1878-1880 \ldots \ldots . .$. & 113 & 247 & 11 & 30,5 & 66,6 & 2,9 \\
$1923-1925 \ldots . .$. & 603 & 465 & 4 & 56,3 & 43,4 & 0,3 \\
\hline
\end{tabular}

Fuente: Dirección General de Agricultura (1866-1880 y 1926-1928).

No todos los pueblos extremeños aceptaron sin más la fiscalización de los ingresos o la individualización de los disfrutes, pero lo cierto es que, a lo largo del primer cuarto del siglo xx, disminuyó sensiblemente la generalizada resistencia de las corporaciones locales a la actuación de los ingenieros. Las fuentes consultadas impiden saber con exactitud por qué los ayuntamientos de la región acabaron tolerando la injerencia de la administración forestal en las superficies municipales no enajenadas. Está claro que la creciente presencia de la guardia civil en el mundo rural pudo ser decisiva a la hora de asegurar el mayor cumplimiento de la legalidad vigente, aunque no parece que el incremento de la vigilancia llegara a ser tan determinante como para subrogar el ánimo de las autoridades locales. Resulta más lógico pensar que fueron los propios ayuntamientos de la zona los que comenzaron a mostrar una actitud menos renuente hacia la intervención del Estado. Creo que este nuevo talante tuvo mucho que ver con las necesidades económicas de la hacienda local y con las reclamaciones de quienes no habían podido acceder a la plena propiedad de los montes desamortizados.

Hay que tener en cuenta que los gobiernos liberales, además de vender las fincas de propios y, con ello, las principales fuentes de ingresos de los ayuntamientos, dejaron en manos de las corporaciones locales la financiación de la mayor parte de los servicios municipales ${ }^{40}$. No es de extrañar, por tanto, que, ante la falta de compensación, los responsables de la hacien-

${ }^{40}$ Véase García García y Comín (1995), pp. 90-104. 
da local concentraran sus esfuerzos en obtener recursos de los bienes todavía no privatizados, aceptando y, a la larga, fomentando la imposición de las subastas en la adjudicación de los aprovechamientos. Por otra parte, es razonable pensar que el propio sistema de licitación pudo ser el único instrumento legal con el que contaron los nuevos grupos emergentes de la sociedad extremeña para garantizar, frente al resto de los miembros de la comunidad, la individualización de los aprovechamientos en los montes subsistentes. Máxime, cuando, al amparo del proceso privatizador abierto tras la publicación de la Ley de 1 de mayo de 1855 , el mundo rural comenzó a padecer internamente las graves consecuencias sociales de la progresiva desarticulación del sistema comunal.

Entre ellas, fue la proletarización del campesinado la que con más fuerza arraigó en el suroeste peninsular. A ello contribuyó, por supuesto, la propia economía de dehesa, caracterizada por la adaptabilidad, pero también por la baja productividad y por la escasa capacidad para absorber mano de obra ${ }^{41}$. Bajo tales condiciones, el mercado consiguió dominar las relaciones laborales en Extremadura desde fechas muy tempranas. Ahora bien, mientras funcionaron los sistemas tradicionales de regulación de los espacios colectivos, el salario de los trabajadores del campo pudo ser completado con el producto extraído del aprovechamiento comunal. Por el contrario, a medida que fueron desapareciendo las superficies destinadas al disfrute libre y gratuito de todos los miembros de la colectividad, también fueron aumentando los lazos de dependencia existentes entre la familia campesina y el ingreso salarial. No cabe duda que la lucha contra el estrechamiento de tales vínculos estuvo siempre presente en las diferentes formas de resistencia que adoptaron los sectores más desfavorecidos de la sociedad extremeña frente al avance del individualismo agrario. Fue, sin embargo, a principios de la pasada centuria, cuando la proletarización pasó a ocupar el primer plano de la protesta y cuando la defensa de los aprovechamientos comunales cedió temporalmente protagonismo a la defensa de los derechos de los trabajadores.

El despegue definitivo del movimiento obrero desde principios del siglo XX quedó marcado en el suroeste peninsular por un incremento sustancial de la conflictividad organizada y por un aumento considerable del asociacionismo reivindicativo. En un primer momento, el régimen conservador intentó contener el arranque de la movilización a través de la sindicación católica y a través de la represión civil, pero ni una ni otra

${ }^{41}$ Puede verse, al respecto, Llopis y Zapata (1998), pp. 61-62. 
pudieron evitar el escoramiento del campesinado extremeño hacia la izquierda. Es más, al término de la I Guerra Mundial, coincidiendo con la caída de los salarios reales provocada por la inflación posbélica y con la crisis del sistema político de la Restauración, Extremadura se convirtió en uno de los enclaves socialistas más activos del país. La fiebre asociativa logró movilizar a los trabajadores del campo en defensa de mejoras salariales, reducción de jornadas, abolición de contrataciones a destajo o imposición de salarios mínimos. Las viejas formas de subversión individual y colectiva (atentados contra la propiedad y ataques contra el propietario) pudieron así ser reforzadas e, incluso, sustituidas por una nueva estrategia de lucha cuyo máximo exponente fue la huelga de brazos caídos ${ }^{42}$.

Con la dictadura de Primo de Rivera, el reforzamiento del principio de autoridad en los campos españoles y el endurecimiento de la normativa reguladora de la actividad pública consiguieron paralizar momentáneamente la fuerza del movimiento obrero regional. La reivindicación organizada en defensa de los derechos laborales de los trabajadores del campo entró entonces en una fase de letargo, pero no desapareció totalmente. Tampoco lo hizo, ni mucho menos, la memoria colectiva. En la mente de los extremeños siguió latiendo la protesta contra la desaparición de una parte sustancial de la riqueza rústica municipal. Ni la oligarquía agraria, ni el Estado liberal, ni la administración forestal, ni el Registro de la Propiedad, ni la guardia civil lograron borrar los linderos del aprovechamiento común. De hecho, cuando la II República permitió esclarecerlos, el movimiento obrero y la memoria colectiva conjugaron esfuerzos, no sólo para recuperarlos, sino también, más que nunca, para extenderlos.

\section{CONCLUSIONES}

Frente a las tesis que tienden a sobrevalorar la capacidad del Estado liberal para imponer por decreto las relaciones capitalistas de producción y para asegurar, al mismo tiempo, la explotación racional de los recursos generadores de externalidades positivas, el ejemplo extremeño revela, no sólo que la penetración del mercado en el mundo rural precedió a la aparición del liberalismo, sino que, incluso, a pesar de los fuertes impulsos que recibió el forestalismo público europeo por parte de los gobiernos decimonónicos, en la práctica, la intervención técnica de los espacios tra-

${ }^{42}$ Véase García Pérez, Sánchez Marroyo y Merinero (1985), pp. 981-986, y Baumeister (1996), pp. 300-368. 
dicionalmente destinados al aprovechamiento colectivo tuvo que seguir contando con la comunidad para poder aplicar mínimamente los principios de la ciencia forestal.

Como en otras muchas zonas del país, la coexistencia de tendencias individualizadoras y comunalizadoras a mediados del siglo XIX resultó ser decisiva a la hora de articular los mecanismos de actuación del Estado en el proceso de redefinición de los derechos de propiedad. Si la vía privatizadora acabó respondiendo a las aspiraciones del liberalismo en tierras del suroeste peninsular no fue tanto por la capacidad de la Administración central para lograr una aplicación homogénea de la norma como por la coincidencia de intereses entre las máximas autoridades del país y las oligarquías agrarias de la región. Aun así, la enajenación masiva de los bienes municipales no aseguró por sí misma la libre inserción de los factores de producción en los circuitos del mercado. Una vez roto el consenso entre los antiguos usuarios del patrimonio municipal, tan sólo la represión armada de las tendencias comunalizadoras pudo garantizar mínimamente la explotación privada de las fincas desamortizadas.

El éxito de la intervención estatal fue mucho menos homogéneo en lo referente a la gestión técnica de la producción. En este caso, ni la presencia activa de la administración forestal ni la creciente militarización del mundo rural lograron imponer por sistema los principios del forestalismo público europeo en las superficies municipales extremeñas. Únicamente, el progresivo acercamiento de posturas entre ingenieros, ayuntamientos y vecinos pudo facilitar la regularización de los aprovechamientos más importantes y la recaudación pacífica de los impuestos sobre la producción. Para ello, los técnicos tuvieron que aceptar la realización de ciertas prácticas hasta entonces negativamente valoradas por la ciencia (aumento de la carga ganadera e incremento de la superficie cultivada) y los usuarios debieron renunciar a parte de los principios adquiridos a través de la experiencia (gratuidad de los disfrutes y reparto vecinal de las cuotas de explotación).

La adaptación de las directrices emanadas de la superioridad a las condiciones de partida puso en entredicho la universalidad de los principios asumidos por el liberalismo en el proceso de redefinición de los derechos de propiedad. Ahora bien, qué duda cabe que, al activar el debate sobre el futuro de los bienes de titularidad pública, la legislación privatizadora obligó a clarificar las diferencias existentes en el seno de cada comunidad. En un principio, la tradicional cohabitación de tendencias individualizadoras y comunalizadoras, no siempre equilibrada, pero sí generalmente respetada en virtud de la costumbre y de la variedad productiva de la 
dehesa, pudo ser mantenida bajo la apariencia de la uniformidad mediante la articulación de estrategias legales destinadas a impedir la intervención estatal. Muy pronto, sin embargo, la participación de los potentados locales en las subastas de las fincas nacionalizadas acabó radicalizando las formas de protesta de los más desfavorecidos. La batalla legal frente a las injerencias del Estado quedó así ampliamente superada por los delitos contra la propiedad desamortizada y los atentados contra la explotación de las superficies forestales intervenidas.

La polarización social a la que finalmente condujo la desarticulación de los sistemas tradicionales de aprovechamiento colectivo no supuso, en la práctica, la ruptura total de las relaciones económicas establecidas entre las partes contendientes, sino que reforzó aún más los lazos de dependencia de los nuevos desposeídos frente a los antiguos poseedores. La reducción de las entradas procedentes de los espacios destinados al uso libre y gratuito de los miembros de la comunidad apuntaló a la fuerza los vínculos existentes entre la familia campesina y el ingreso salarial. La lucha reivindicativa contra el estrechamiento de tales vínculos pasó a ocupar, a partir de entonces, el primer lugar de la protesta frente al avance del individualismo agrario. Con ello, la legislación liberal contribuyó indirectamente al incremento sustancial de la resistencia organizada en los campos del suroeste peninsular. Quizá el fortalecimiento del movimiento obrero no estuvo nunca presente en los planes del liberalismo económico. En términos de costes de transacción, por ejemplo, parece lógico pensar que los gastos derivados de la defensa de los derechos de propiedad recientemente definidos debieron aumentar de manera significativa como consecuencia del agravamiento de la conflictividad rural. Desde este punto de vista es posible restar importancia a las consecuciones generalmente atribuidas por la historiografía española a la política económica del Estado liberal. Pero la cuenta de resultados no quedaria completa si, al producto final, no sumáramos también la materialización en tierras extremeñas de un objetivo conscientemente perseguido: la liberalización del mercado de trabajo.

\section{BIBLIOGRAFÍA Y FUENTES}

AgunERA, F. (1991): «¿La tragedia de la propiedad común o la tragedia de la malinterpretación en economía?», Agricultura y Sociedad, núm. 61, pp. 157-181. Araque, E. (1990): Los montes públicos en la Sierra de Segura. Siglos XIX y XX, Granada, Universidad de Granada. 
ArTIAGA, A. (1991): A desamortización na provincia de Pontevedra (1855-1900), Pontevedra, Diputación de Pontevedra.

BALBOA, X. (1990): O monte en Galicia, Madrid, Xerais de Galicia.

BarRanTES, V. (1875): Aparato Bibliográfico para la Historia de Extremadura, Madrid, Pedro Núñez.

Bauer, E. (1980): Los montes de España en la Historia, Madrid, Ministerio de Agricultura.

BAumeister, M. (1996): Campesinos sin tierra. Supervivencia y resistencia en Extremadura (1880-1923), Madrid, Ministerio de Agricultura.

Berkes, F. (ed.) (1989): Common Property Resources. Ecology and Community-Based Sustainable Development, Belhaven Press.

Campos, P. (1984): Economía y energía en la debesa extremeña, Madrid, Ministerio de Agricultura.

Casals, V. (1988): Defensa y ordenación del bosque en España. Ciencia, Naturaleza y Sociedad en la obra de los Ingenieros de Montes durante el siglo XIX, Barcelona, Universitat de Barcelona.

- (1996): Los ingenieros de montes en la España contemporánea, 1848-1936, Barcelona, Ediciones del Serbal.

Cobo, F.; Cruz, S., y GonzÁlez de Molina, M. (1992): «Privatización del monte y protesta campesina en Andalucía Oriental», Agricultura y Sociedad, núm. 65, pp. 253-302.

Corona, G. (1996): «Il posseso collectivo della terra nell'Italia contemporanea: linee generali d'interpretazione», en J. J. BusquedA y E. VICEDo (eds.), Bens comunals als Països Catalans $i$ a l'Europa contemporània, Lleida, Institut d'Estudis Ilerdencs, pp. 529-551.

Diario de Sesiones (1870): Diario de Sesiones de las Cortes Constituyentes. Legislatura 1869-1870, Madrid, Imprenta de J. A. García.

- (1874): Diario de Sesiones de las Cortes Constituyentes de la República Españala, Madrid, J. A. García.

- (1880): Diario de Sesiones de las Cortes Constituyentes. Legislatura 18541856, Madrid, Viuda e Hijos de J. A. García.

DíEz EsPINOSA, J. R. (1986): Desamortización y economia agraria castellana. Valladolid, 1855-1968, Valladolid, Diputación de Valladolid.

Dirección General de Agricultura (1859): Clasificación general de los Montes Públicos, Madrid, Imprenta Nacional.

- (1864): Catálogo de los Montes Públicos Exceptuados de la Desamortización, Madrid, Imprenta Nacional.

- (1866-1887): Estadisticas de la producción de los montes públicos (1861-1880), Madrid, Colegio de Sordo-Mudos, El Correo y Manuel Minuesa.

- (1901): Catálogo de los montes y demás terrenos forestales exceptuados de la desamortización por razones de utilidad pública, Madrid, Sucesora de Manuel Minuesa.

- (1926-1928): Estadísticas generales de la producción de los montes públicos. Años forestales 1923-1924, 1924-1925 y 1925-1926, Madrid, Imprenta Cervantina.

Dirección General de Propiedades (1897): «Relaciones de los montes y demás terrenos forestales de dominio público que no revisten carácter de interés general», Gaceta de Madrid, núms. 233 y 237. 
Elena, M.; Bureau, E., y López, J. A. (1980): «La crisis del sistema productivo de dehesa», en A. DE BARros (ed.), Agricultura latifundiária na Peninsula Ibérica, Oeiras, Fundação Calouste Gulbenkian, pp. 287-301.

GarCí GARCiA, C., y Comin, F. (1995): «Reforma liberal, centralismo y haciendas municipales en el siglo XIX», Hacienda Pública Española, núm. 133, pp. 81-106.

GARCía PÉrEZ, J. (1986): «Desaparición y permanencia de bienes comunales (Dehesas Boyales) en la provincia de Cáceres a la luz de los expedientes de excepciones civiles (1856-1870)», en Desamortización y Hacienda Pública, Madrid, Ministerio de Agricultura y Ministerio de Economía y Hacienda, vol. II, pp. 199-216.

- (1994): Las desamortizaciones eclesiástica y civil en la provincia de Cáceres (1836-1870), Cáceres, El Brocense.

Garcia Pérez, J.; Sánchez Marroyo, F., y Merinero, M. J. (1985): Historia de Extremadura. IV. Los tiempos actuales, Badajoz, Universitas.

GIMÉNEZ, C. (1990): «La polémica europea sobre la comunidad aldeana, 1850-1900», Agricultura y Sociedad, núm. 55, pp. 9-63.

Gómez Mendoza, J. (1992): Ciencia y política de los montes españoles, Madrid, Ministerio de Agricultura.

Grossi, P. (1986): Historia del derecho de propiedad. La irrupción del colectivismo en la conciencia europea, Barcelona, Ariel.

Hardin, G. (1968): «The Tragedy of the Commons», Science, vol. 162, pp. 1243-1248.

Interrogatorio (1851): Interrogatorio sobre Bienes de Propios de la Provincia de Badajoz, Madrid, Archivo del Congreso de los Diputados.

INVENTARIO (1855): Inventario de los montes de la provincia de Cáceres, realizado en cumplimiento del Real Decreto de 26 de octubre de 1855, Cáceres, Archivo de la Diputación Provincial de Cáceres.

IRIARTE, I. (1996a): «Derechos de propiedad y bienes comunales (El caso de Navarra entre 1861 y 1935)», en J. Pujol, P. FATJó y N. EsCANDELl (eds.), Cambio Institucional e Historia Económica (VIII Simposio de Historia Económica), Barcelona, Universitat Autònoma de Barcelona, pp. 321-342.

IRIARTE, I. (1996b): Bienes comunales y capitalismo agrario en Navarra, 1855-1935, Madrid, Ministerio de Agricultura.

JAMES, N. D. G. (1990): A bistory of English Forestry, Oxford, Blackwell.

JimÉnez Blanco, J. I. (1991): «Los montes de propiedad pública (1833-1936)», en F. Comín y P. Martín Aceña (dirs.), Historia de la empresa pública en España, Madrid, Espasa Calpe.

Jiménez Blanco, J. I. (1996): Privatización y apropiación de tierras municipales en la Baja Andalucía. Jerez de la Frontera, 1750-1995, Jerez de la Frontera, Ayuntamiento de Jerez de la Frontera.

KALAORA, B., y SAVOYE, A. (1986): La forêt pacifiée: sylviculture et sociologie au XIX siècle, París, L'Harmattan.

LANA, J. M. (1992): «Los aprovechamientos agrícolas comunales en el Sur de Navarra entre los siglos XIX y XX», Agricultura y Sociedad, núm. 65, pp. 65-99.

LLOPIS, E., y ZAPATA, S. (1998): «Raíces históricas del atraso económico de Extremadura», Situación (Extremadura), Madrid, Banco Bilbao Vizcaya, pp. 53-71. 
López Estudillo, A. (1992): «Los montes públicos y las diversas vías de su privatización en el siglo XIX», Agricultura y Sociedad, núm. 65, pp. 65-100.

MCCaY, B. J., y ACHerson, J. M. (eds.) (1987): The Questions of the Commons. The Culture and Ecology of Communal Resources, The University of Arizona Press.

MANUEL, C. (1994): La propiedad rústica pública en los sectores central y meridional de la Sierra de Madrid (Siglos XVIII-XX), Madrid, Universidad Autónoma de Madrid.

MARTín Galindo, J. L. (1966): «La dehesa extremeña como tipo de explotación agraria», Estudios Geográficos, núm. 103, pp. 157-226.

MaYaud, J. L. (1996): «Les communaux en France du Xvire au $x x^{e}$ siècle», en J. J. Busqueda y E. ViCEdo (eds.), Bens comunals als Països Catalans i a l'Europa contemporània, Lleida, Institut d'Estudis Mlerdencs, pp. 553-577.

Montiel, C. (1990): Los montes de utilidad pública en la provincia de Alicante, Alicante, Universidad de Alicante.

MORENO, J. R. (1992): «Los ingenieros de montes en la segunda mitad del siglo XIX. Desamortización civil y administración forestal», $V$ Reunión del Seminario de Historia Agraria, Santiago de Compostela.

MoRenO, J. R. (1996): «Dinamismo del régimen comunal y autorregulación concejil: la Sierra de Cameros durante el siglo XVIII y XIX», en J. PUjOL, P. Fatjó y N. Escandell (eds.), Cambio Institucional e Historia Económica (VIII Simposio de Historia Económica), Barcelona, Universitat Autònoma de Barcelona, pp. 395-421.

NEESON, J. M. (1996): «Common right in England 1700-1820: recent findings, new questions», en J. J. BusQuedA y E. VICEDo (eds.), Bens comunals als Països Catalans $i$ a l'Europa contemporània, Lleida, Institut d'Estudis Ilerdencs, pp. 513-527.

Nieto, A. (1964): Bienes Comunales, Madrid, Revista de Derecho Privado.

Planes de Aprovechamientos (1873-1925): Planes Provisionales de Aprovechamientos Forestales (Provincias de Badajoz y Cáceres), Madrid y Alcalá de Henares, Archivo del Ministerio de Agricultura y Archivo General de la Administración.

Propios, Arbitrios y Comunes (1835-1855): Expedientes de Propios, Arbitrios y Comunes. Años 1835-1855, Badajoz y Cáceres, Archivo de la Diputación Provincial de Badajoz y Archivo de la Diputación Provincial de Cáceres.

RELACION (1846): Relación clasificada de todos los montes existentes en la Provincia de Cáceres, Cáceres, Archivo de la Diputación Provincial de Cáceres.

Rodrigues, M. (1987): Os baldios, Lisboa, Caminho.

SABIO, A. (1997): Los montes públicos en Huesca (1859-1930). El bosque no se improvisa, Huesca, Instituto de Estudios Altoaragoneses.

SALA, P. (1995): «Tragèdia del comunals i tragèdia dels tancaments, dilema del presoner i cooperació no altruista. Un estat de la qüestió sobre la propietat comunal», Recerques, núm. 33, pp. 137-147.

- (1997): «Conflictividad rural en el monte comunal gerundense: pueblos y mansos ante el Estado interventor en la segunda mitad del siglo XIX», Noticiario de Historia Agraria, núm. 13, pp. 105-124. 
- (1998): Sobre la compatibilitat entre bosc productor i bosc protector (La Catalunya forestal bumida entre la societat agrària $i$ la societat industrial, 1850-1930), Barcelona, Universitat Autònoma de Barcelona.

SÁNCHEZ MARROYO, F. (1992): Movimientos populares y reforma agraria. Tensiones sociales en el campo extremeño durante el Sexenio Democrático (1868-1873), Badajoz, Diputación de Badajoz.

SAnZ Fernández, J. (1986): «La historia contemporánea de los montes públicos españoles, 1812-1930. Notas y Reflexiones (I)», en R. GarRabOU y J. SANZ FERNÁNDEZ (eds.), Historia agraria de la España contemporánea. II. Expansión y crisis (1850-1900), Barcelona, Crítica, pp. 193-228.

Thompson, E. P. (1975): Whigs and Hunters. The Origin of the Black Act, London, Allen Lane.

- (1984): Tradición, revuelta y conciencia de clase, Barcelona, Crítica.

- (1991): Customs in common, London, The Merlin Press.

ZapaTA, S. (1986): La producción agraria en Extremadura y Andalucia Occidental, Universidad Complutense de Madrid. 